Council should also provide that the programmes of work of the several sections are properly co-ordinated, and that the projected investigations of Caribbean problems are approached with the view of yielding early results. Secondly, the activities of the Caribbean Research Council and the implementation of its findings depend ultimately on an enlightened public opinion among the Caribbean peoples themselves, and therefore on an improvement of their educational standards. Thirdly, the Research Council should give due consideration to the related work of institutions outside the Caribbean area and to such international agencies as may be created in pursuance of proposals made by the Hot Springs Conference on Food and Agriculture.

The extent to which opinion in the Caribbean is becoming aware of the research needs of the area may be seen in a number of proposals made by delegates in the reports of the committees dealing with other items on the agenda of the Conference. The committees concerned with means for raising the nutritional level both included such proposals in their reports. That dealing with increased local food production urged that research in the development and adaptation of foods of high nutritional and protective value and in cognate matters should be intensified through the medium of the Caribbean Research Council, and the necessary personnel provided to undertake extended programmes of research. That concerned with expansion of fisheries, after endorsing the findings of the Fishery Committee of the AngloAmerican Caribbean Commission meeting at St. Thomas last August, urges that its recommendations should be implemented without delay. The Fishery Experimental Station at Mayaguez, Puerto Rico, should be a centre for technological research and a bureau for the collection and dissemination of statistics and information as well as undertaking fundamental and biological research. The most pressing lines of research are, in technology, on the capture of fish and on its handling and preservation; in biology, biological research which is necessary for the intelligent development and conservation of the fisheries, including studies on dominant species of fish, fish histories, productivity and depletion, migrations, seasonal schooling and spawning, and environmental studies on contrasted types of fishing grounds. Besides research in oceanography, such as an ecological study of the environments in which fish live, longterm fundamental research will be necessary to provide background information for the intelligent management and development of the fisheries, and as an informed basis for measures of conservation. The establishment of a fishery research institute in the British West Indies will be necessary, and such a scheme should be co-ordinated with any plans for the establishment of a University of the West Indies, or it should be affiliated to the Imperial College of Tropical Agriculture. Fishery research institutes and experimental stations should frame their research policy in accordance with the practical needs of the industry and co-ordinate their programmes on a regional basis.

This sectional report also recommends that an exploratory fishery survey in the Bahamas and Caicos, investigations on fish handling and preservation and net preservation, under local conditions, and on the commercial possibilities of sharks, crawfish, conchs, turtle and shrimp should be undertaken without delay; and that the attention of the Caribbean Research Council should be directed to the necessity for collecting and disseminating information on the commercial possibilities of sharks, the crawfish industry in the Bahamas, fresh and brackish water fish-culture and on sport fishing.

The report of the committee which considered the planning of public works for the improvement of agriculture, education, housing and public health includes a recommendation for the establishment of a Caribbean Planning Commission as part of the AngloAmerican Caribbean Commission. It also recommends the institution for research on standardization of building units in various materials and the possibility of prefabricating such units in the Caribbean area, including the scientific pretreatment of lumber and standardized timber units against termite and rot at depots in each territory or group of islands.

The committee which considered industrial development recommends that the Government should help to create and to foster new industries and the development of existing industries which could survive without continued State assistance, either by undertaking research itself or by supporting approved investigations, the results of which should be made available at once to the whole area. Such research might include the erection of pilot plants at the public expense.

These and other recommendations of the sectional committees were adopted by the Conference, which further recommended that another session should be held within twelve months, and that the AngloAmerican Caribbean Commission should consider the establishment of a permanent secretariat to handle the work of the Conference. Besides the emphasis thus laid on research, however, the Conference is of more than local interest as an example of Colonial regionalism in which an effective expression is given to the democratic spirit.

\section{POSSIBLE RELATION OF LINOLENIC ACID TO THE LONGEVITY AND GERMINATION OF PINE SEED}

\author{
By DR. N. T. MIROV \\ U.S. Forest Service
}

CEEDS of some pines, such as Jeffrey pine (Pinus $\$$ jeffreyi), can be stored in air-tight jars at room temperature for a long time. Even after ten years of storage one may expect as much as 40 per cent of viable seed. When the seeds of Jeffrey pine are sown in a greenhouse they germinate rapidly and abundantly. Many other pines, as, for example, sugar pine (Pinus lambertiana), have short-lived seed. Under ordinary storage conditions sugar pine seeds lose their viability rapidly, and after five years of storage their germination is usually nil. At $5^{\circ} \mathrm{C}$. the viability of sugar pine seed is maintained for a long time ; in one case, after eight years of cold storage, germination amounted to 86 per cent of the original. Normally seeds of sugar pine sown in a greenhouse either fail to germinate completely or give a very small percentage of germination. When, however, the seeds are chilled in some moist medium for three months at $5^{\circ}$ C., they germinate as well as those of Jeffrey pine. This prolonged period at a low temperature, necessary for germination of refractory seeds, can be designated as the period of incipient germination. 
Food storage materials of seed of the two pines are composed chiefly of fatty oil $(55.5$ per cent in sugar pine seed and 50 per cent in Jeffrey pine seed), proteins and sugars. It is seen that more than one half of the reserve food material in seeds of both pines consists of oil, and that sugar pine has more of it than Jeffrey pine. Analyses have shown that the oil of sugar pine seed has an iodine value of 150.5 while the oil of Jeffrey pine seed has an iodine value of $136 \cdot 4$. There is thus a higher degree of unsaturation in the seed oil of sugar pine.

In ordinary storage the most unsaturated component of the pine seed oil-linolenic acid-disappears gradually in all seeds but more rapidly in sugar pine than in Jeffrey pine seed. In the seeds of both species stored at $5^{\circ} \mathrm{C}$., on the contrary, no appreciable losses in linolenic acid were detected. When sugar pine seeds were chilled in moist sand for three months, only traces of linolenic acid were found at the end of that period. Prolonged storage at ordinary temperatures results in decrease of germination capacity of sugar pine seed, whereas chilling in moist sand results in an increase; yet in both cases linolenic acid disappears.

Although a possible role of unsaturated fatty acids and especially of linolenic acid in germination and longevity of oleaginous seed has received very little attention, its importance in biological oxidation has been emphasized by Meyerhof ${ }^{1}$. This author discussed at length Warburg's findings that "of all the unsaturated acids, linolenic acid alone with its three double linkages shows autoxidation with iron". During autoxidation the number of double bonds decreases and the reaction proceeds as follows :

$$
\begin{aligned}
& \mathrm{CH}_{3} \cdot \mathrm{CH}_{2} \cdot \mathrm{CH}=\mathrm{CH} \cdot \mathrm{CH}_{2} \cdot \mathrm{CH}=\mathrm{CH} \cdot \mathrm{CH}_{2} \cdot \mathrm{CH}=
\end{aligned}
$$

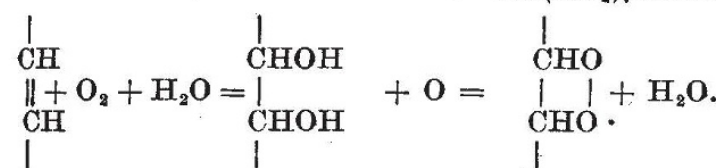

Meyerhof distinguishes between the reaction in vitro where it stops on the conversion of linolenic acid into slightly oxidized products, and a reaction in vivo where it progresses as far as formation of carbon dioxide.

In stored seed where life processes are hindered, conditions perhaps are similar to those existing in vitro. Slightly oxidized produets are formed and these are gradually polymerized into inactive substances. The degradation of the unsaturated acids, and especially of the linolenic acid, proceeds faster in sugar pine seed than in Jeffrey pine seed. During the incipient period of germination of sugar pine seed the conditions may be similar to a reaction in vivo. Here disappearance of linolenic acid is probably connected with respiration and also with transformation of fats into carbohydrates.

The final results in both cases are precisely the same, namely, disappearance of linolenic acid, but the course of oxidation is quite different. In one instance it possibly causes death of the seed, while in the other it probably represents the first stage of germination connected with the utilization of stored food materials.

Of course, variations in linolenic acid contents in the seed of the two pines do not explain yet why Jeffrey pine seed germinates well under ordinary conditions and sugar pine seed does not. The experi- ments show that it might be connected with differences in the status of growth hormone in the seeds of the two species, but the discussion of this phase of germination is beyond the scope of this paper.

"Meyerhof, Otto, "Chemical Dynamics of Life Phaenomena" (Philadelphia and London, J. B. Lippincott Co., 1924).

\section{ASSOCIATION OF UNIVERSITY PROFESSORS AND LECTURERS OF THE ALLIED COUNTRIES IN GREAT BRITAIN}

\section{ANNUAL MEETING}

$\mathrm{T}$

HE fifth general meeting of the Association of University Professors and Lecturers of the Allied Countries in Great Britain was held in Cambridge during June 24 and 25,1944 . It was the annual meeting, a sequel to the annual meeting of 1943 held in Oxford, and a special significance was attached to it as a friendly gathering, as well as a business meeting, in view of the not unreasonable expectation that the members may have separated to their own countries before the next annual meeting falls due.

The morning of June 24 opened with meetings of Section IV (Student Affairs), chairman, Prof. R. D. Laurie (Great Britain); Section VIII (Modern Humanities), chairman, Prof. L. E. Genissieux (France); and Section IX (History), chairman, Dr. de Sturler (Belgium). Then all Sections met for a lecture on the history of the Cavendish Laboratory by Sir Lawrence Bragg. The afternoon followed the same pattern : meetings of Section II (Collaboration with International Bodies), chairman, Prof. J. Timmermans (Belgium); Section V (Law), chairman, Prof. B. Helczynski (Poland); Section VI (Science and Technology), chairman, Prof. A. Photiades (Greece); and Section VII (Economy), chairman, Prof. J. A. Veraart (Netherlands), and after tea in the gallery of Emmanuel College a lecture by Prof. G. M. Trevelyan on the history of the University of Cambridge.

On June 25 the General Assembly met, and was welcomed by the vice-chancellor, Dr. T. S. Hele, master of Emmanuel College.

The president of the Association, Prof. J. Timmermans, then gave his address, which was a résumé of the year's work and progress. He pointed out that it has been a period of consolidation but that also there have been new departures. The Executive Committee had found sufficient work to require a meeting each month, with two in May. An Education Conference was held in April on lines similar to that held in the spring of 1943, and the British Council again guaranteed a very considerable contribution towards defraying the cost of publishing the report. The Publicity Committee, under the chairmanship of Prof. Photiades, carried through the publication of Communication, addressed to members, of which three numbers have already appeared and of which some half-dozen are planned to be produced during twelve months. Prof. Timmermans reviewed the activities of members of the Executive Committee in relation to other organizations having similar interests, notably the Conference of Allied Ministers of Education, the London International Assembly, the British Association Committee on Post-War 